\title{
Effect of Compaction Banding on the Hydraulic Properties of Porous Rock: Part I-Experimental Investigation
}

\author{
Julia Leuthold ${ }^{1}$ (1) $\cdot$ Eleni Gerolymatou ${ }^{2} \cdot$ Maximiliano R. Vergara $^{1,3} \cdot$ Theodoros Triantafyllidis $^{1}$
}

Received: 19 March 2020 / Accepted: 1 March 2021 / Published online: 23 March 2021

(c) The Author(s) 2021

\begin{abstract}
The mechanical behavior and the influence of compaction banding on the hydraulic properties in soft porous rocks were studied. The tested rock was Calcarenite Tuffeau de Maastricht. In the frame of experimental investigations, triaxial and oedometric tests were conducted under dry and drained conditions. The results demonstrated that the rock is forming discrete compaction bands under high confining stresses and steep angle shear bands under low confining stresses. Permeability measurements during the oedometric and triaxial compression tests under drained conditions demonstrated that the axial permeability decreases with increasing axial strain. The maximum permeability decrease was three orders of magnitude for $40 \%$ of axial strain.
\end{abstract}

Keywords Compaction band $\cdot$ Rock permeability $\cdot$ Grain crushing $\cdot$ Strain localization $\cdot$ Porous rocks

\section{Introduction}

The permeability of rock is of paramount importance to a variety of applications, such as oil and gas exploitation, $\mathrm{CO}_{2}$ storage, and geothermal energy exploitation. Most of these applications are linked to large depths and, as a result, to high stresses. The initial in situ stress is disturbed not only by the construction of the necessary boreholes, but also by the production itself, which leads to a significant variation of the effective stress. Under such conditions, the likelihood of material yield increases, especially as far as the formation of compaction bands is concerned, since the in situ mean pressure is high.

Compaction bands are thin tabular strain zones of localized deformation with negligible shear offset. They have been observed in the field, for example in Aztec Sandstone in Nevada Sternlof (2006), in Navajo Sandstone in Utah Antonellini et al. (1994), and in the Orange area in France

Julia Leuthold

julia.leuthold@kit.edu

1 Karlsruhe Institute for Technology, Engler-Bunte-Ring 14, 76131 Karlsruhe, Germany

2 Chalmers University of Technology, Sven Hultins gata 6, 41258 Gothenburg, Sweden

3 Present Address: Ed. Zueblin AG, Albstadtweg 3, 70567 Stuttgart, Germany
Ballas et al. (2012). The compaction bands observed in situ were up to $100 \mathrm{~m}$ long and $1-10 \mathrm{~mm}$ thick. The formation of compaction bands has also been studied in the laboratory, e.g., in quartz sandstones (Klein et al. 2001; Baud et al. 2004; Olsson and Holcomb 2000; Bésuelle et al. 2000), carbonate rocks (Baxevanis et al. 2006; Cilona et al. 2012; Papazoglou et al. 2017; Baud et al. 2009; Vajdova et al. 2012), and mudstone (Oka 2011). The results demonstrated that the response changes from brittle to ductile with increasing confining stress. The formation of compaction bands was observed under high confining stresses, but under low confining stresses, the formation of shear bands was observed. The formation of compaction bands has also been documented in other materials like gas foam (Forest et al. 2005), honeycombs (Papka and Kyriakides 1999), and snow (Barraclough et al. 2016).

The influence of compaction bands on the hydraulic properties of the material has been investigated in the field and in the laboratory. Ballas et al. (2012) studied the permeability decrease in naturally occurring shear enhanced compaction bands in the Orange area in France. They observed a decrease in permeability in the bands by up to 4 orders of magnitude in comparison with the intact rock. Holcomb and Olsson (2003) studied the permeability evolution in Castelgate Sandstone in triaxial tests. They observed a permeability decrease with increasing axial strain by up to two or three orders of magnitude. Furthermore, the results showed that 
the decrease in permeability begins with the onset of plastic deformation and terminates with the end of the compaction process accompanied with the beginning of the hardening process. Another study by Baxevanis et al. (2006) investigated the permeability evolution in triaxial tests on Calcarenite Tuffeau de Maastricht. The measured decrease in permeability was under one order of magnitude at an axial strain of $1.5 \%$. It must be noted that the test ended before the compaction process was completed. A comparison of the various studies shows that the results are contradictory, as to the magnitude of the permeability reduction. Therefore, one objective of this study was to find out whether the permeability of Calcarenite decreases with further deformation and whether a decrease in permeability of 2-3 orders of magnitude can be achieved. To establish a relation between the compaction process and the decrease of permeability in the rock, the relation between void ratio and permeability is often described by the Kozeny-Carman (Kozeny 1927; Carman 1997) equation. However, Baxevanis et al. (2006) already observed deviations from the Kozeny-Carman law at rather small strains. This may be due to non-uniform strains in the specimen or to grain crushing. In different studies, the investigation of thin sections indicates that compaction can lead to grain crushing in the compaction bands (Klein et al. 2001; Menéndez et al. 1996). Grain crushing increases the specific surface and could be taken into account in the Kozeny-Carman equation. Therefore, the compaction process is also studied with thin sections on a micro scale.

\section{Tested Rock}

The tested rock is Calcarenite Tuffeau de Maastricht, a yellowish carbonate grain stone with a high porosity and a weak cementation between the grains. Figure 1 shows a picture of the rock in a block.
The rock is from a quarry in Maastricht and all specimens are cored from the same block. The initial porosity of the rock is $52 \%$ and the mineralogical composition is $98 \%$ calcite. The material was selected, because, according to other studies by Baxevanis et al. (2006) and Papazoglou et al. (2017), the rock fails by the formation of compaction bands under high confining stresses perpendicular to the bedding. From a thin section, a mean grain size of 100 $\mu \mathrm{m}$ was measured.

\section{Experimental Test Setups and Specimen Preparation}

To investigate the mechanical properties, uniaxial compression tests, triaxial compression tests, and a hydrostatic compression test were conducted on dry specimens. For these tests, an MTS 0815 testing system was used. Figure 2 shows a picture of the machine.

The setup can apply a maximum axial load of $4600 \mathrm{kN}$ and a maximum confining pressure of $140 \mathrm{MPa}$. The local axial deformation and the local circumferential deformation are measured with extensometers on the specimen in the lower and upper third partition and in the middle of the specimen, respectively. In Fig. 2 the extensometers for the local deformation measurements are shown. The chain around the midsection of the specimen is for the circumferential strain measurement and the bridge above for the measurement of the axial strain. The local axial strain was measured over a length of $50 \mathrm{~mm}$.

The cylindrical specimens were cored perpendicular to the bedding and had a height of $140 \mathrm{~mm}$ and a diameter of $69 \mathrm{~mm}$. The uniaxial and triaxial compression tests were all conducted under strain control at a displacement rate of $0.1 \mathrm{~mm} / \mathrm{min}$, while the hydrostatic test was stresscontrolled at a loading rate of $2.04 \mathrm{MPa} / \mathrm{min}$. The repetition of single triaxial compression tests at low and at high
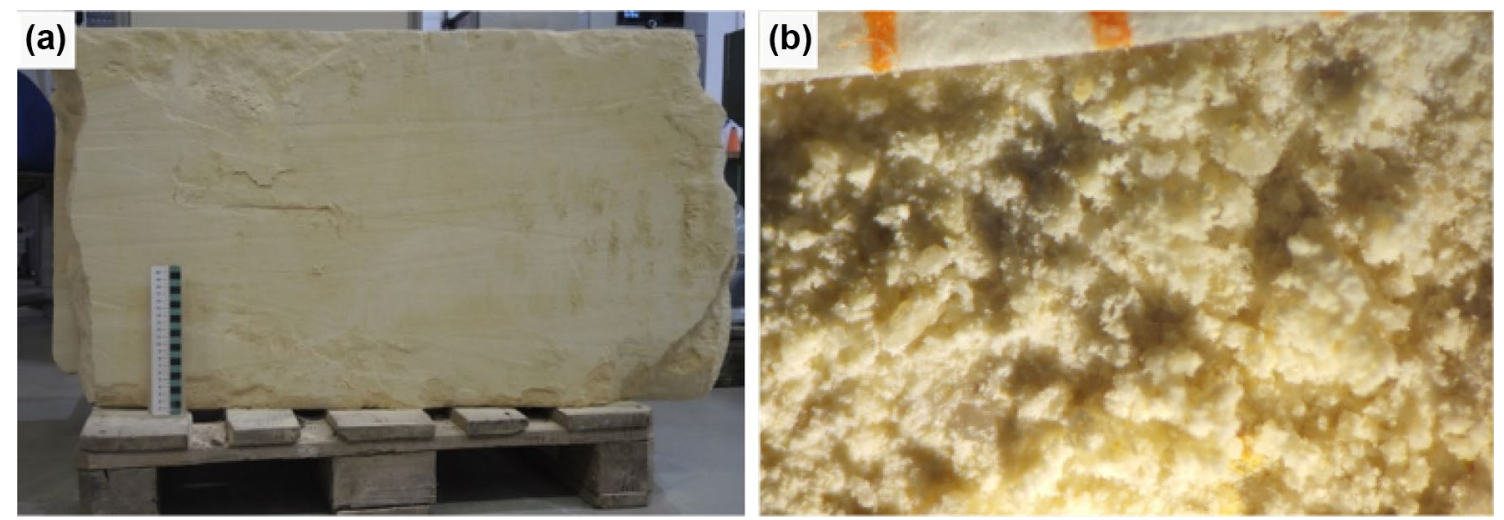

Fig. 1 Maastricht Calcarenite: a block material; $\mathbf{b}$ picture with a microscope and graph paper 
Fig. 2 left: testing apparatus used for the triaxial tests under dry conditions; right: specimen with local deformation measurement devices in the testing machine
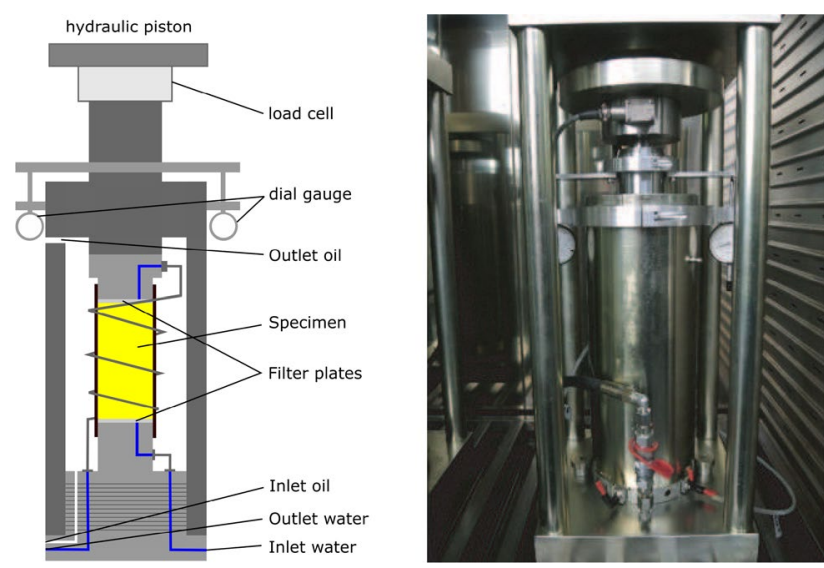

Fig. 3 Test setup used for the triaxial tests under drained conditions

confining pressures showed that the reproducibility of the mechanical behavior is good and that there is no significant material scattering. Therefore, only one specimen was tested for each confining pressure.

To investigate the influence of compaction banding on the hydraulic properties, drained triaxial tests on water saturated specimens were performed. For these tests, a different test device was used. In this test device, the axial displacement is controlled manually. The displacement of the piston in vertical direction is applied with a hydraulic hand pump and the confining stress with an electrically driven oil pressure pump. Figure 3 shows a sketch and a photograph of the used test setup for the drained triaxial tests.

The global axial strain is measured by means of two external dial gauges rigidly connected to the vertical piston. However, the stiffness of the piston is high compared to that of the specimen. Local measurements were not performed. The cylindrical specimens were again cored perpendicular to the bedding. They had a height of $100 \mathrm{~mm}$ and a diameter of $50 \mathrm{~mm}$. The specimens were prepared in the same way as those for the triaxial tests under dry conditions. The loading plates were equipped with filter plates made of stainless steel from the company SIPERM with a thickness of $5 \mathrm{~mm}$, a porosity of $50 \%$, and a permeability of $10^{-6} \mathrm{~m} / \mathrm{s}$. For the tests, de-mineralized and de-aerated water was used. The specimen was first placed under vacuum with a vacuum pressure of $-0.08 \mathrm{MPa}$ and then saturated at a pore pressure of $0.2 \mathrm{MPa}$ on both of its sides. This procedure ensured that the specimen had a saturation degree of $98 \%$. The axial permeability was measured in increments of $1 \%$ axial strain. The permeability measurements were stationary and the pore pressure on both sides of the specimens was at least 0.2 $\mathrm{MPa}$, so that the specimens were continuously saturated. For the calculation of the permeability, the change of the specimen height as well as the pressure loss in the system were considered. The tests were stopped at an axial strain of $10 \%$.

In addition to triaxial tests, oedometric tests under dry conditions were performed within this study. In an oedometer test, the specimen is placed in a steel ring, so that the strain in radial direction is inhibited. The ring is made of stainless steel, and has a height of $20 \mathrm{~mm}$, an inner diameter of $60 \mathrm{~mm}$, and a thickness of $5 \mathrm{~mm}$. The specimens were 
cored perpendicular to the bedding and had a height of 19 $\mathrm{mm}$ and a diameter of $60 \mathrm{~mm}$. The test was performed using the MTS 0815 testing machine with a displacement rate of $0.1 \mathrm{~mm} / \mathrm{min}$.

Drained oedometric compression tests with permeability measurements were performed on saturated specimens. For the compression test, two different test devices were used. One test device, called test setup 01, is a test device where the axial stress is applied manually with a wheel and the axial strain is measured at the axial piston by means of a dial gauge (Vergara et al. 2014). The maximum load cell capacity of the test device was $50 \mathrm{kN}$. In test setup 02 , the axial stress is applied with a hydraulic pump and the maximum load is $200 \mathrm{kN}$. The axial strain is also measured with a dial gauge. In Fig. 4, a sketch of the specimen in the ring and in the oedometer cell and a picture of test setup 01 and test setup 02 are shown.

The specimens were cored perpendicular to the bedding and had a height of $20 \mathrm{~mm}$ and a diameter of $60 \mathrm{~mm}$. The specimen was set in a ring made of steel with an inner diameter of $60 \mathrm{~mm}$ and a thickness of $10 \mathrm{~mm}$. To ensure a good fit of the specimen in the ring, the ring was heated to up to $200^{\circ}$ before inserting the specimen without confinement into the ring. Analytical calculations that considered the heating of the steel ring result in a pre-stress in radial direction of 200 $\mathrm{kPa}$ after cooling to room temperature. The load plates were equipped with filter plates as in the drained triaxial tests. The saturation of the specimen was performed as in the drained triaxial tests. The permeability was measured at increments of $1 \%$ axial strain. The test had to be stopped when the axial load reached the maximum load cell capacity.

To conduct permeability measurements of specimens with larger deformation, another testing procedure, called test setup 03, was followed. The specimens were initially compressed oedometrically under dry conditions. A thicker ring with $40 \mathrm{~mm}$ inner diameter and $15 \mathrm{~mm}$ wall thickness was used to avoid plastic deformation of the ring during loading. Subsequently, the specimens were taken out of the machine and installed in test setup 02 . There, the specimen was fixed in axial direction with an axial stress of $3 \mathrm{kN}$ and saturated in the same manner like the other specimens described above. Then, the permeability of the compacted specimens was measured with the measurement device of the drained oedometer tests. In this way, it was possible to measure the permeability of specimens which have a final axial deformation under dry conditions of up to $39 \%$. To verify the test results and to quantify the effect of saturated conditions during the compaction process, a second oedometer test was performed using the test setup 02 . With test setup 02 , it was possible to deform the water saturated specimen inside the cell in the axial direction to an axial strain of $40 \%$ and to measure the permeability of the deformed saturated specimens.

\section{Experimental Results}

In this study, triaxial compression and oedometer tests under dry as well as under drained conditions were performed. The procedure and results are presented in this section.

\subsection{Uniaxial, Isotropic, and Triaxial Compression Tests Under Dry Conditions}

First results from compression tests under dry conditions are presented. Figure 5 shows four specimens that were tested under triaxial conditions at different confining pressures. The failure mode of the specimens indicates a transition

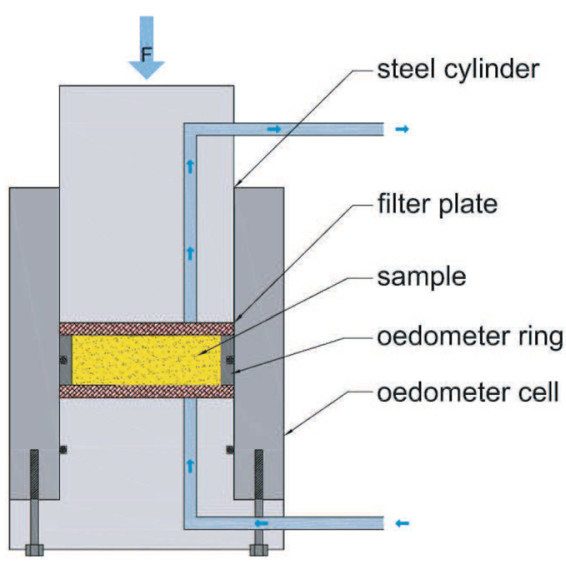

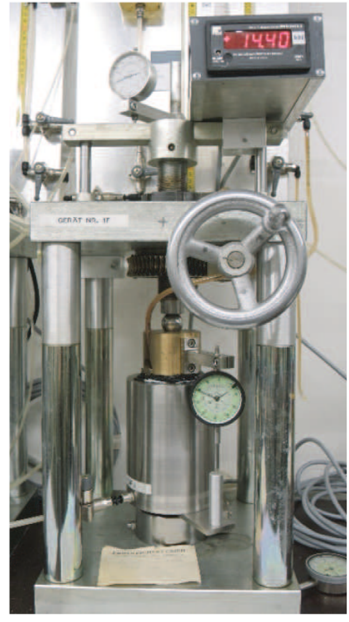

Test setup 01

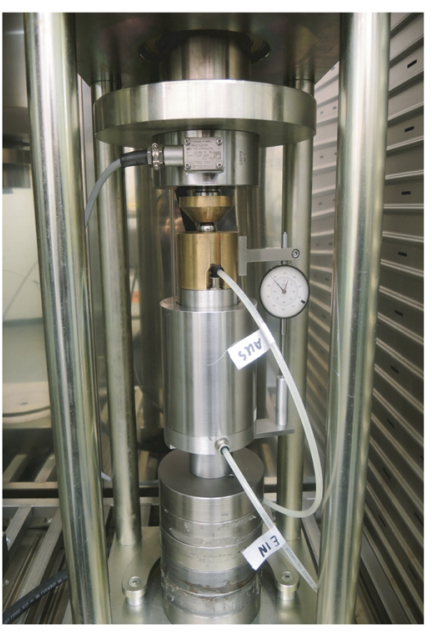

Test setup 02

Fig. 4 Schematical view of the oedometer test, test setup 01 with a maximum load of $50 \mathrm{kN}$, and test setup 02 with a maximum load of $200 \mathrm{kN}$ 
Fig. 5 specimens after the triaxial tests at different confining pressures, from left to right: uniaxial, 1.0 MPa, 1.5 MPa, and $2.5 \mathrm{MPa}$


from shear to compaction failure with increasing confining stress. The specimen in Fig. 5a was tested in uniaxial compression and failed forming a steep angle shear band. The second specimen (Fig. 5b) was tested at a confining stress of $1 \mathrm{MPa}$ and failed as well by forming a steep angle shear band, even though the inclination of the shear band to the vertical axes in this case seems to be somewhat smaller than for the specimen in Fig. 5a. The third specimen in Fig. 5c was tested at $1.5 \mathrm{MPa}$ and presents the formation of lowangle diffuse shear bands in the upper part of the specimen. The specimen shown in Fig. 5d was tested at a confining stress of $2.5 \mathrm{MPa}$ and shows several horizontal compaction bands in the upper part. The lower part looks intact.

The compaction bands in the specimen were discrete and the cementation locally dissolved as a result of the compaction process. This led to the formation of discontinuities in the specimen that opened when the specimen was unloaded. The failure pattern indicates that the compaction process started at the upper part of the specimen and propagated downwards with increasing axial strain. In Fig. 6, the response curves of the different uniaxial tests are presented. In Fig. 6a, the deviatoric stress is plotted against the external axial strain. One test was performed controlling the axial strain rate and the other test controlling the circumferential strain rate.The advantage of the circumferential strain control is the fact that the post-failure response can be followed more closely. Instead of the abrupt stress reduction usually observed, in this case, the decrease of the axial strain during inelastic deformation can be clearly seen. Figure $6 \mathrm{~b}$ shows the circumferential strain plotted against axial strain for both test methods. The values for the circumferential strain are similar for both tests, but the different control variables are visible in the curve progression. Figure 7 shows the specimens after both uniaxial compression tests. In Fig. 7a, the specimen that was tested under circumferential strain control and, in Fig. $7 \mathrm{~b}$, the specimen after the axial strain controlled test are shown. The pictures demonstrate that both specimens failed by the formation of a steep angle shear band. On a more detailed visual examination of the specimen in Fig. 7a, it was found that the fracture had a discontinuous inclination and propagated from imperfection to imperfection on the surface of the specimen. In the other specimen, no correlation could be established between the imperfections of the rock and the geometry of the shear band.
Fig. 6 Results of uniaxial compression tests with different test methods, with axial strain rate control and with circumferential strain rate control: a axial stress plotted against axial strain; $\mathbf{b}$ circumferential strain plotted against axial strain

Fig. 7 The specimens after the uniaxial compression tests: a circumferential strain controlled and $\mathbf{b}$ axial strain controlled

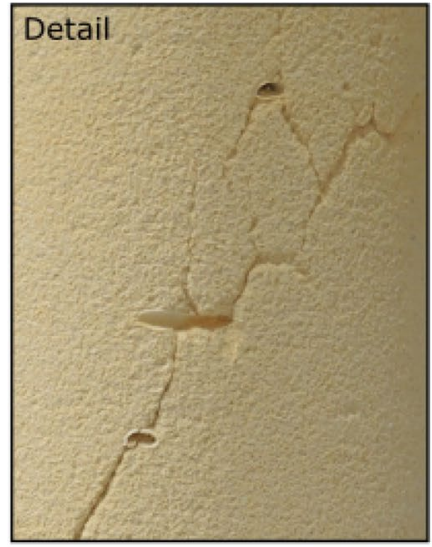

(a)

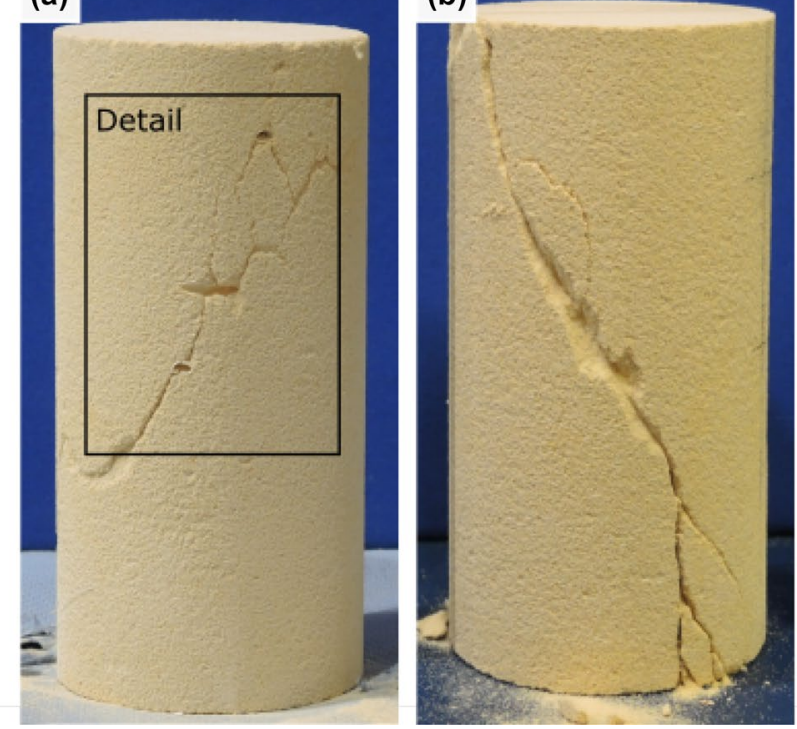

Fig. 8 Results of triaxial compression tests with different confining pressures: a small values for the confining pressure and brittle failure behavior; $\mathbf{b}$ high values for the confining pressures and ductile failure behavior

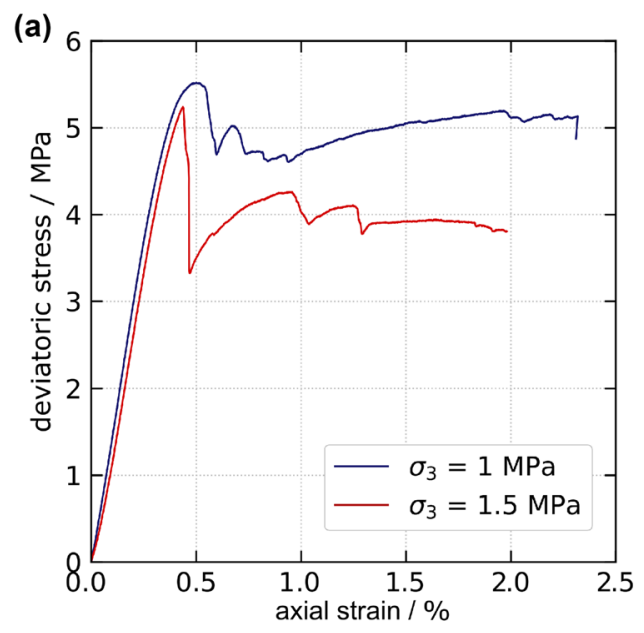

In Fig. 8a, the differential stress is plotted against the axial strain for low confining pressures up to $1.5 \mathrm{MPa}$. The failure is brittle for the test performed at a confining pressure of $1 \mathrm{MPa}$. For the triaxial test at a confining pressure of $1.5 \mathrm{MPa}$, the behavior observed is between brittle and ductile, as the initial reduction in axial stress is only slight and subsequently followed by a plateau. The results of triaxial tests at high confining pressures are given in Fig. 8b. The overall response is ductile and plateaus of different lengths were observed in all tests. It is assumed that the spontaneous stress drops observed in the curve progression are a result of the formation of compaction bands in the specimens, which further indicates the formation of discrete rather than diffuse zones of localized deformation. The hardening phase starts at the end of the plateau, which becomes shorter for higher confining pressures. This means that there is less axial deformation in the compaction process under increasing confining pressure. Figure 9 shows pictures of the specimens after the triaxial tests with different confining pressures. Several discrete compaction bands are visible in all specimens. Figure 10 shows the results of the isotropic compression tests. In Fig. 10a, the confining pressure is plotted against external axial strain. The stress response is typical for an isotropic test and differs from the one of the triaxial tests, because the stress increases further after the yield point, meaning that the hardening starts with the onset of plastic deformation. In Fig. 10, volumetric strain is plotted against mean stress. The volumetric strain is calculated under the assumption of a homogeneous deformation behavior in the inelastic deformation regime. This means that the volumetric strain is calculated with the results of the local strain measurements in radial and in axial direction: $\epsilon_{\mathrm{v}}=\epsilon_{\mathrm{r}}+\epsilon_{\mathrm{a}}$, with $\epsilon_{\mathrm{r}}$ for radial strain and $\epsilon_{\mathrm{a}}$ for local axial strain. The experimental results of the present study 
are plotted together with those from Papazoglou (2018) who used the same material. The comparison of the results shows that the behavior from the stress-controlled tests and the one from Papazoglou (2018) are similar to each other. After the test, no discrete compaction band was visually observed in the specimen and no destructuration was visible at the initial inspection. However, after being placed in water, the specimen fell apart, indicating that debonding had taken place.

In Fig. 11, the local strain measurements during different compression tests are plotted against the external axial strain. The circumferential strain is plotted against the external axial strain in Fig. 11a. Since the specimens are
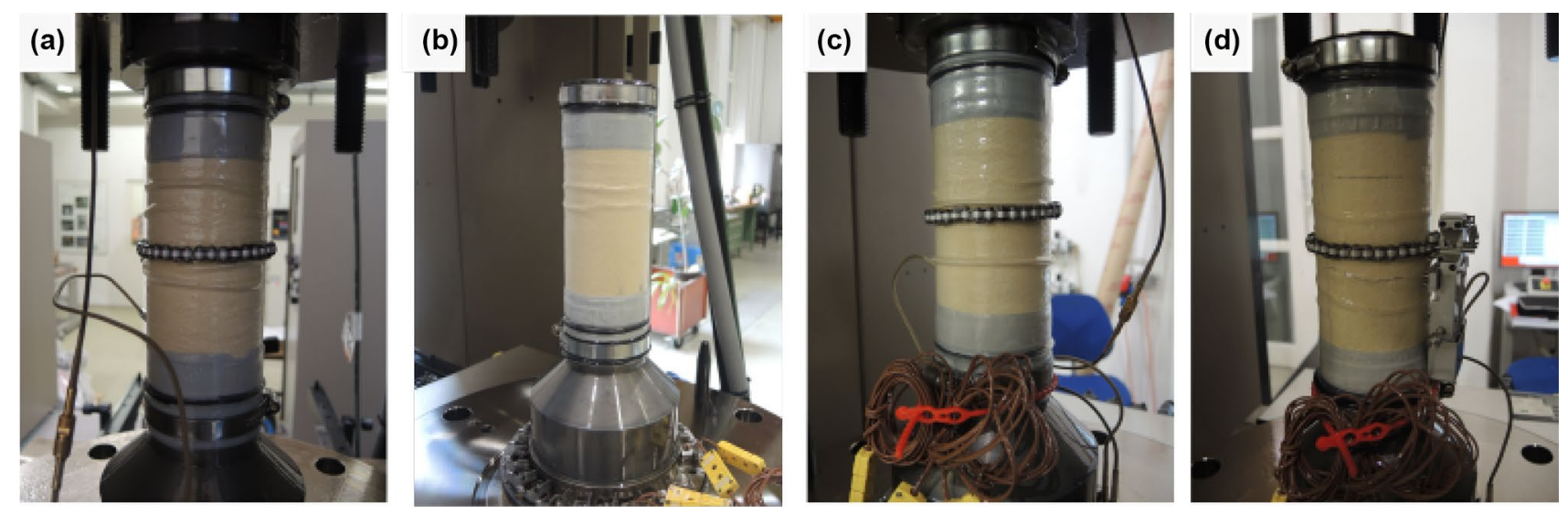

Fig. 9 The specimens after triaxial compression tests with different confining pressures: a $3.25 \mathrm{MPa}$; b $4 \mathrm{MPa}$; c $5 \mathrm{MPa}$; d $6 \mathrm{MPa}$

Fig. 10 Results of isotropic compression tests with different test methods: a confining pressure plotted against axial strain; b volumetric strain plotted against mean stress together with experimental results from Papazoglou (2018) (a)

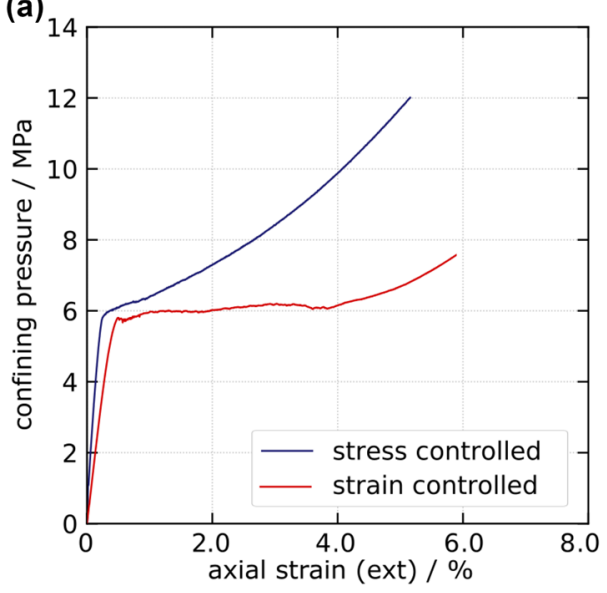

(a)

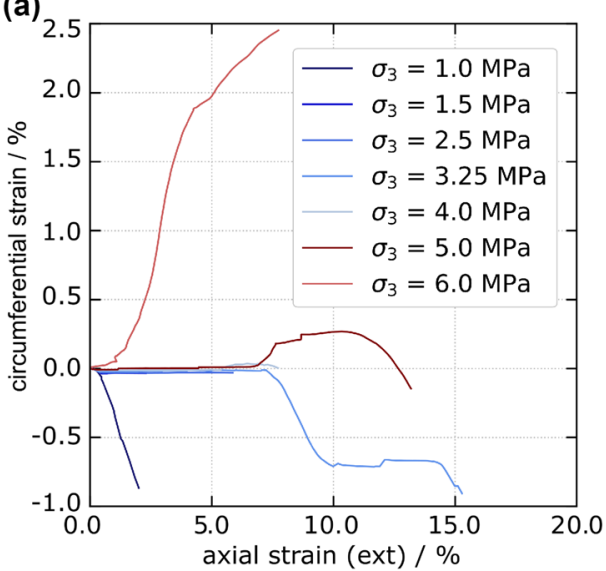

(b)



(b)



measurements on the surface of the specimen: a circumferential strain plotted against external axial strain; b local axial strain plotted against external measured axial strain 
cored perpendicular to the bedding plane and the material is homogeneous on the macro scale, it can be assumed that the circumferential strain is equal to the radial strain. In triaxial compression tests with low confining pressures, such as $1 \mathrm{MPa}$, the circumferential strain increases during the inelastic deformation, as a result of the formation of shear fractures. In the tests under higher confining pressures, the circumferential strain stays constant at the onset of plastic deformation. As shown by the failure pattern of the specimen tested at 2.5 MPa confining pressure in Fig. $5 \mathrm{~d}$, the compaction process begins at the upper end of the specimen, and with increasing axial deformation, the compaction zone propagates to the middle. The circumferential strain is measured in the middle of the sample. Therefore, the circumferential strain begins to change as soon as the compaction front has reached the middle of the specimen. In the test at a confining pressure of $3.25 \mathrm{MPa}$, the circumferential strain shows extensions when the compaction process in axial direction reaches the middle of the specimen, then remains constant as the rest of the specimen compacts, and increases again when the whole specimen is fully compacted and the hardening starts. In the visual inspection of the specimen, a discrete compaction band under the chain was observed, and additionally, the sleeve showed a fold at the band. This could have influenced the measurement. For higher confining stresses, $5 \mathrm{MPa}$ and $6 \mathrm{MPa}$, the circumferential stress decreases when the compaction front reaches the middle of the specimen and increases when the hardening of the specimen begins. When comparing the results of the different tests, during the plateau phase, radial extension at 'low' confining pressures and radial compaction at 'high' confining pressures is documented. The onset of the deformation takes place earlier with increasing confining stress, as one would expect from the fact that the stress plateaus become shorter with increasing confining stress.

For some triaxial tests, the local axial strain was measured with two extensometers on the surface of the specimen. These measurements are used to investigate the influence of the boundary conditions at the end plates on the measurement. In Fig. 11b, the axial strain measured with extensometers for different confining pressures is plotted against the axial strain measured by the displacement of the axial piston. In the test with a confining pressure of $1 \mathrm{MPa}$, the local axial strain increases monotonically from the beginning of the test. However, the inclination of the curve is smaller than 1.0, meaning that the axial strain measured with the displacement of the piston is larger than the axial strain measured with the extensometers. This could be due to the friction between the end plates and the specimen, but is most likely a result of the smaller stiffness of the interface between end plates and specimen. In the tests with high confining pressure, the axial strain of the extensometers stays constant from the onset of plastic deformation. This is also a result of the localized deformation, because the compaction process starts at the upper part of the specimen. When the compaction front reaches the measurement range of the local axial strain, the axial strain increases again. For the measurement of the elastic modulus and the Poisson's ratio, unloading and reloading cycles have been conducted in the elastic part of the compression tests. In Table 1, the elastic parameters are presented for different confining pressures. The elastic modulus, the Poisson ratio, the secant modulus, and the bulk modulus were measured externally and locally. The fraction of the global modulus to the local modulus ranges from 0.37 to 0.75 . This means that the local stiffness is in all cases significantly higher than the global one. It can also be stated that the global secant moduli do not exhibit a marked dependence on the confining pressure.

\subsection{Triaxial Compression Tests Under Water Saturated Conditions}

In the following, the results of drained triaxial tests with different confining pressures and with saturated specimens are presented. The results demonstrate that the failure mode is the same under water saturated as under dry conditions. In Fig. 12, the mean stress is plotted against the axial strain for four different confining pressures.Under the confining pressure of $2.5 \mathrm{MPa}$, the material response was ductile. In every specimen, compaction bands were observed, with small ruptures that are a result of the destruction of the cementation between the grains. In Fig. 13, three specimens after

Table 1 Elastic parameters

\begin{tabular}{llllllll}
\hline Test & $E_{\text {local }}(\mathrm{MPa})$ & $E_{\mathrm{glob}}(\mathrm{MPa})$ & $v_{\text {local }}(-)$ & $E_{\mathrm{s}, \mathrm{loc}}(\mathrm{MPa})$ & $E_{\mathrm{s}, \text { global }}(\mathrm{MPa})$ & $E_{\mathrm{v}, \text { loc }}(\mathrm{MPa})$ & $E_{\mathrm{v}, \mathrm{glob}}(\mathrm{MPa})$ \\
\hline Uniaxial & 2730 & 1000 & 0.20 & 2913 & 1247 & - & - \\
$1 \mathrm{MPa}$ & - & - & - & 3163 & 1431 & - & - \\
$2.5 \mathrm{MPa}$ & - & - & - & 3017 & 1511 & - & - \\
$3.25 \mathrm{MPa}$ & - & 1160 & 0.17 & - & 1645 & - & - \\
$4 \mathrm{MPa}$ & 3524 & 2647 & 0.14 & - & 1451 & - & - \\
$5 \mathrm{MPa}$ & - & - & - & - & 1494 & - & - \\
$6 \mathrm{MPa}$ & - & - & - & - & 1152 & - & - \\
Hydrostatic & - & - & - & - & - & 4647 & 3123 \\
\hline
\end{tabular}




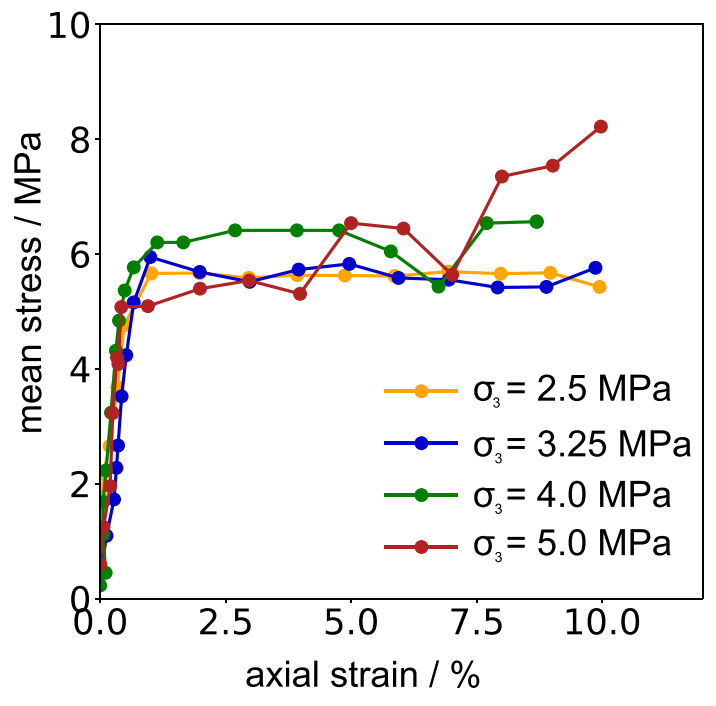

Fig. 12 Results of the drained triaxial tests with different confining pressures and mean stress plotted against axial strain
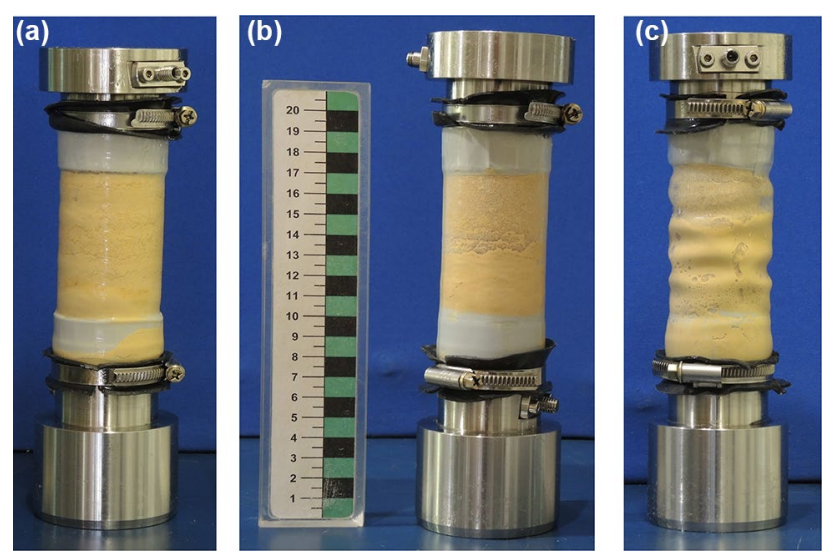

Fig. 13 The specimens after the triaxial compression test under drained conditions at different confining stresses, from left to right: 2.5 $\mathrm{MPa}, 3.25 \mathrm{MPa}$, and 5.0 $\mathrm{MPa}$

the triaxial tests at different confining pressures are shown. The entrapment of air voids, which can be observed in the specimen in Fig. 13c, is a result of the unloading after the test, when the pore pressure was set to zero. The specimen in Fig. 13c, close to the plastic onset of the wet rock, exhibits a strong deformation in the radial direction.

\subsection{Failure Locus}

To determine the tensile strength of the rock, indirect tensile strength test was conducted under dry conditions. For these tests, a uniaxial testing machine was used that has a maximum testing force in the axial direction of $550 \mathrm{kN}$ and a regulation range for the displacement rate from 0.001 to $500 \mathrm{~mm} / \mathrm{min}$. The tests were performed according to the
Table 2 Results of the tensile strength test perpendicular to the bedding

\begin{tabular}{llll}
\hline & Maast-Z-1 & Maast-Z-2 & Maast-Z-3 \\
\hline Dry weight $(\mathrm{g})$ & 472.05 & 474.08 & 475.59 \\
Water content $(\%)$ & 0 & 0 & 0 \\
$\rho_{d}\left(\mathrm{~g} / \mathrm{cm}^{3}\right)$ & 1.29 & 1.28 & 1.27 \\
Diameter $(\mathrm{mm})$ & 97.30 & 97.00 & 97.60 \\
Length $(\mathrm{mm})$ & 49.40 & 50.00 & 50.00 \\
$\mathrm{~F}_{\text {max }}(\mathrm{kN})$ & 2.668 & 2.419 & 2.665 \\
$\sigma_{\mathrm{t}}(\mathrm{MPa})$ & 0.35 & 0.32 & 0.35 \\
\hline
\end{tabular}

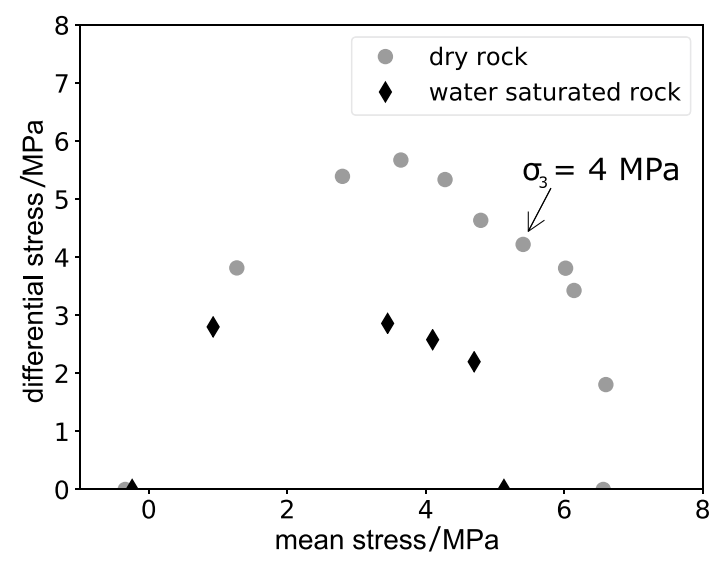

Fig. 14 The yield loci for the dry and the water saturated rock

recommendation of the DGGT Lepique (2008) and the tensile strength is calculated with the following equation:

$\sigma_{\mathrm{t}}=\frac{2 F \pi}{D l}$,

with $F$ as the maximum force, $D$ as the diameter, and as $l$ the length of the specimen. The results of the tensile strength test are given in Table 2.It was not possible to conduct indirect tensile strength tests under drained conditions. With the results of the compression tests and the tensile strength test, it is possible to plot the peak stresses of the water saturated and the dry rock. In Fig. 14, the differential stress is plotted against the mean effective stress and the two yield loci are illustrated.Comparison of the strength of the wet and the dry material indicates that the wet material is failing at lower stresses than the dry specimens. According to different studies (Castellanza and Nova 2004; Cai et al. 2019), this is to be expected, especially in a calcitic material, as in this case. The shape of the yield surfaces shows a cap in both cases. The yield locus of the dry rock appears non-convex in the cap part. Therefore, the triaxial compression test at a 
confining pressure of $4 \mathrm{MPa}$, marked in the figure, was performed a second time and the same value for the peak stress at the onset of plastic deformation was measured in this test.

\subsection{Effect of Compaction Banding on the Permeability}

The permeability during the drained triaxial compression tests with different confining stresses was measured. In Fig. 15, the permeability in the axial direction is plotted in logarithmic scale against the axial strain for four different confining pressures.

As expected, the permeability decreases with increasing axial strain. The permeability of the specimens that have been tested at $2.5 \mathrm{MPa}$ and $3.25 \mathrm{MPa}$ confining stress shows the same response. The other two curves exhibit a different inclination. The permeability of the specimens tested at a confining stress of $4 \mathrm{MPa}$ and $5 \mathrm{MPa}$ show a sharp decrease with the onset of plastic deformation. One reason for this behavior could be the strong deformation of the specimen shown in Fig. 13. The permeability decrease in total is around one order of magnitude. However, as the permeability is still decreasing at an axial strain of $10 \%$, the limit of the test device, it is possible

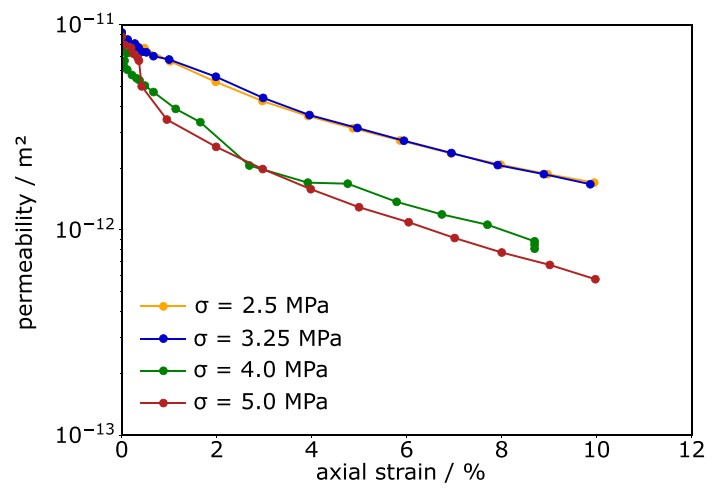

Fig. 15 Permeability versus axial strain for drained triaxial compression that the permeability could decrease further with further deformation.

\subsection{Oedometric Tests}

The results of the oedometric test under dry conditions are qualitatively similar to the ones of the isotropic compression tests, in the sense that no clear plateau and no spontaneous unloadings were observed. The axial stress is plotted against the axial strain in Fig. 16b. After reaching the yield point, the axial stress continues to increase with further deformation. This is to be expected, as the prevention of the lateral displacement leads to an increase of the lateral stress with growing axial strain.

In Fig. 16a, the results of the two oedometer tests under drained conditions in two different test setups are presented. The axial stress is plotted against the axial strain.The unloadings in the stress-strain curve are a result of the strong creep and relaxation of the wet rock between the measuring points. The two curves are very similar. They both form a plateau after reaching the yield point and start showing hardening at an axial strain of $16 \%$. In comparison to the results of the oedometer tests under dry conditions, it can be observed that the rock exhibits a pronounced plateau in the presence of water, which was absent in the dry specimens. At the same time, the stress in the saturated specimens is only slightly lower and the exponential hardening starts at only slightly larger deformations.

Figure 17 shows the results of the permeability measurements of the drained oedometer test in test setup 01, the results of the precompacted specimen (test 01 ), and the results of the oedoemeter test in test setup 02 (test 02).The permeability decrease begins in both curves with the onset of plastic deformation. The curves are close to linear in semi-logarithmic scale, at least until a strain of about $25 \%$, which means that the permeability decreases in the form of a power function. This is different to the results of the drained triaxial tests and can be a result of the increasing lateral stress. As the curve labeled with test 01 and test 03 is forming a plateau at an axial strain of $37 \%$, it could be
Fig. 16 a The axial stress plotted against the axial strain for the oedometer tests under drained conditions: Test 01 stands for the results of the oedometer test in Test Setup 01 and Test 02 stands for the results of the oedometer test in test setup 02. b The axial stress plotted against the axial strain from an oedometer test under dry conditions
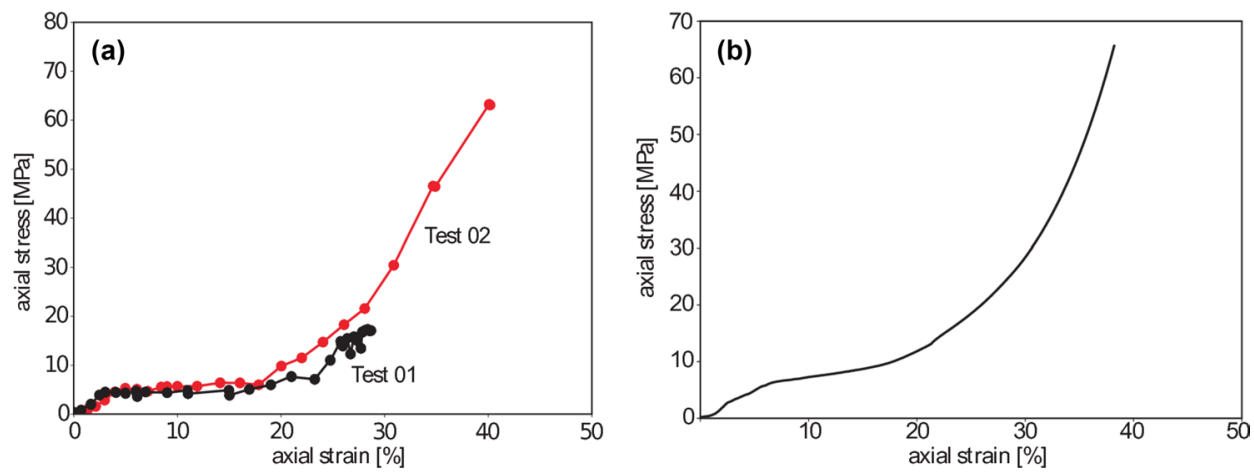


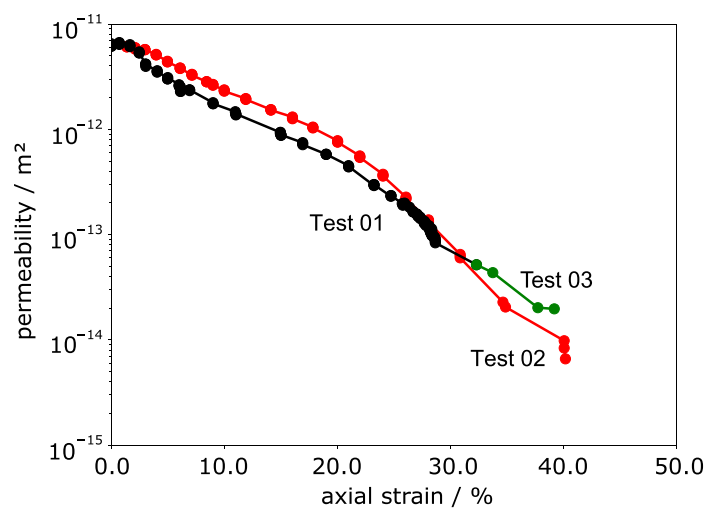

Fig. 17 Permeability in the axial direction against axial strain for three different oedometer tests. In black are the results from tests with normal specimens in test setup 01 and in green the results from tests in test setup 03. The results in red are from a test with a normal specimen in test setup 02

deduced that the permeability is not decreasing as rapidly with further deformation, though additional points would be necessary to assess this conclusion with certainty. That would mean that the compaction process is completed. The complete permeability reduction is nearly three orders of magnitude. In the curve labeled as test 02 , a plateau is not observed. That means that the permeability is decreasing with further deformation. The total permeability decrease is also of about three orders of magnitude. The difference between the two results is small and can be a result of scatter in the mechanical properties of the rock. Especially, the results of the normal compacted and precompacted specimen are in good accordance, even though the test setup and test methods are different.

\subsection{Thin Sections}

Thin sections of the specimens were produced pre- and postmortem using blue epoxy. The main objective of this analysis was to clarify whether and to what extent grain crushing occurs during compaction The thin sections were investigated under a polarized microscope and images were taken for comparison.

Thin sections of the intact rock are compared with thin sections of a specimen compacted in an oedometer test under dry conditions. The blue space is the void space. The intact rock has a initial porosity of 52\% and the compacted rock has a porosity of $36 \%$. Figure 18 a shows an image of a thin section of the intact rock at $\times 100$ magnification and Fig. 18b shows an image of a thin section of the compacted rock with the same magnification. The images of the thin sections show that the grains of the rock have a size of $50-150 \mu \mathrm{m}$ and that they are mostly composed of different fragments of shells and corals. Furthermore, the rock has a
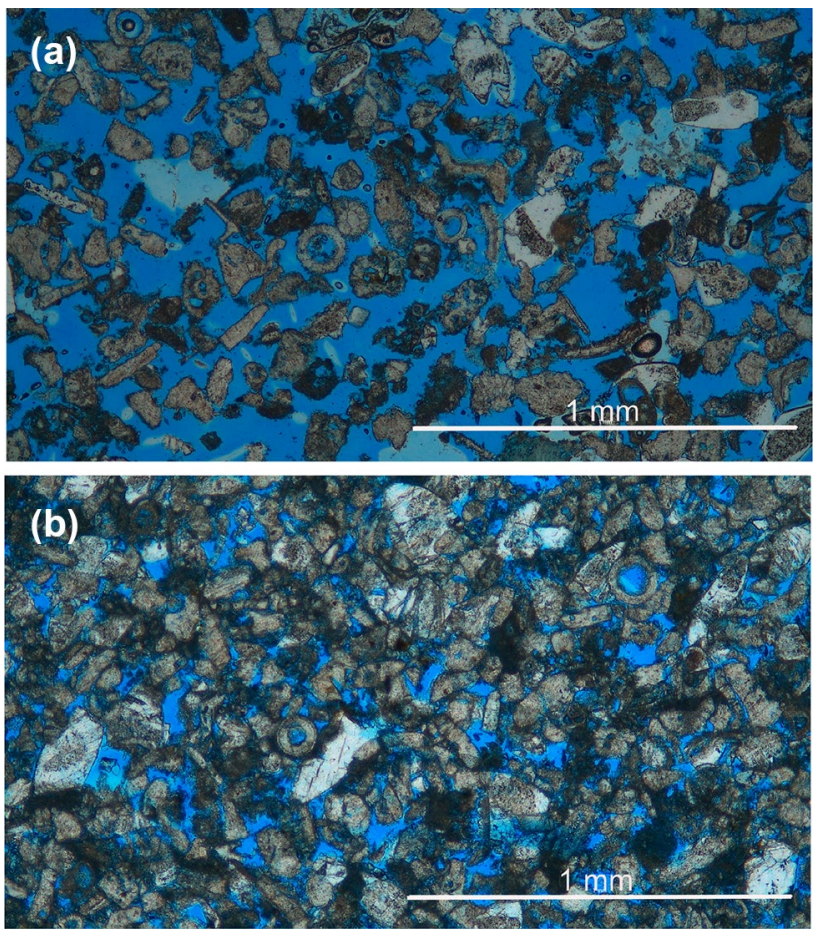

Fig. 18 Thin section of the $\mathbf{a}$ intact rock and the $\mathbf{b}$ compacted rock in an oedometer test at $35 \%$ of axial strain under $\times 100$ magnification; the scale bar is $1 \mathrm{~mm}$. The voids are in blue, because of the used epoxy (color figure online)

high intra-particle porosity within the shell fragments. These structures are from a static point of view more unstable and collapse with compaction of the rock. In the comparison of the two figures in Fig. 18, the decrease of the porosity and also grain breakage are visible.

In Fig. 19, the thin section of the compacted rock with a magnification of $\times 200$ is shown. In the middle of the image, a circular shell fragment that has been fragmented during the test is visible. Other fragmented grains are also visible in the figure, with examples marked in red ellipses. The

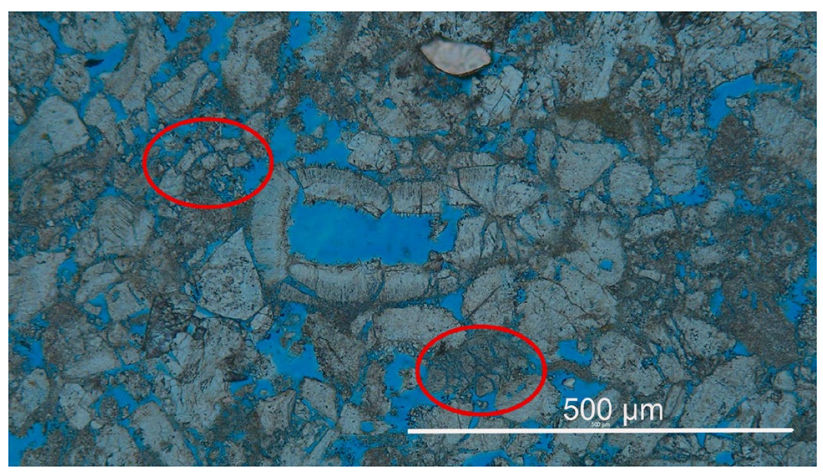

Fig. 19 Thin section of the compacted rock at $35 \%$ of axial strain under $\times 200$ magnification; the scale bar is $500 \mu \mathrm{m}$ 
thin sections demonstrate that pronounced grain crushing is present in the rock during the compaction process in the oedometer test under dry conditions. No thin sections were prepared from the specimens tested under triaxial conditions. In the literature Baxevanis et al. (2006) suggests that some grain crushing takes place, but it would be reasonable to expect a lesser extent of the phenomenon, given the lower mean pressures.

\section{Discussion and Conclusions}

The formation of compaction bands in Calcarenite de Maastricht was studied experimentally, under dry and under drained conditions. The tests demonstrated that under low confining pressures, the rock fails by the formation of steep angle shear bands and the transition from brittle to ductile failure was found to take place at a confining pressure of 1.5 $\mathrm{MPa}$, when the rock failed by the formation of lowangle diffuse shear bands in the upper part of the specimen. Under high confining pressures, the rock exhibits compaction bands. The formation of compaction bands started at the upper end of the specimen and propagated with increasing axial strain to the other side, an effect most likely of the spherical seat at the upper load plate. The higher the confining pressure, the smaller was the ability for deformation in axial direction during the compaction process. After the compression tests, discrete compaction bands were observed in the specimens. This is also supported by the observation of spontaneous stress drops in the strain controlled triaxial tests. They can be an effect of the heterogeneity of the rock or an intrinsic characteristic of the material. It is worth noting that the same effect was observed by Baxevanis et al. (2006), albeit in drained conditions, while Papazoglou et al. (2017) observed a continuous propagation of the compaction front.

In parallel to these tests, triaxial tests under drained conditions with high confining pressures, to ensure the formation of compaction bands, were conducted with a different test setup. In these tests, the evolution of the permeability with increasing axial strain was measured. The results demonstrated that the permeability decreases with increasing axial strain about one order of magnitude at an axial strain of $10 \%$. To investigate the permeability decrease with further axial deformation, oedometer tests under drained conditions were conducted. The results demonstrated a decrease of the permeability of 3 orders of magnitude at 39\% axial strain. This shows that the compaction of porous rocks can lead to a strong decrease of the permeability. Thin sections performed indicate that, at least in the oedometric tests, grain crushing takes place. This would seem to indicate that the high change in the permeability is linked not only to the reduction of the void ratio but also to an increase in the specific surface. In terms of mechanical response, it was found that wetting of the material results not only in a smaller elastic domain, but also in a yield surface with a different shape.

Acknowledgements The authors would like to thank Prof. Papamichos for bringing the material to our attention and for providing experimental data for comparison.

Funding Open Access funding enabled and organized by Projekt DEAL.

\section{Declarations}

Conflict of interest The authors declare that they have no conflict of interest.

Open Access This article is licensed under a Creative Commons Attribution 4.0 International License, which permits use, sharing, adaptation, distribution and reproduction in any medium or format, as long as you give appropriate credit to the original author(s) and the source, provide a link to the Creative Commons licence, and indicate if changes were made. The images or other third party material in this article are included in the article's Creative Commons licence, unless indicated otherwise in a credit line to the material. If material is not included in the article's Creative Commons licence and your intended use is not permitted by statutory regulation or exceeds the permitted use, you will need to obtain permission directly from the copyright holder. To view a copy of this licence, visit http://creativecommons.org/licenses/by/4.0/.

\section{References}

Antonellini MA, Aydin A, Pollard DD (1994) Microstructure of deformation bands in porous sandstones at Arches National Park, Utah. J Struct Geol 16(7):941-959

Ballas G, Soliva R, Sizun J-P, Benedicto A, Cavailhes T, Raynaud S (2012) The importance of the degree of cataclasis in shear bands for fluid flow in porous sandstone provence, France. AAPG Bull 96(11):2167-2186

Barraclough TW, Blackford JR, Liebenstein S, Sandfeld S, Stratford TJ, Weinländer G, Zaiser M (2016) Propagating compaction bands in confined compression of snow. Nat Phys 13:272-275

Baud P, Klein E, Wong T-F (2004) Compaction localization in porous sandstones: spatial evolution of damage and acoustic emission activity. J Struct Geol 26(4):603-624

Baud P, Vinciguerra S, David C, Cavallo A, Walker E, Reuschlé T (2009) Compaction and failure in high porosity carbonates: mechanical data and microstructural observations. Pure Appl Geophys 166(5-7):869-898

Baxevanis T, Papamichos E, Flornes O, Larsen I (2006) Compaction bands and induced permeability reduction in tuffeau de maastricht calcarenite. Acta Geotech 1(2):123-135

Bésuelle P, Desrues J, Raynaud S (2000) Experimental characterisation of the localisation phenomenon inside a vosges sandstone in a triaxial cell. Int J Rock Mech Min Sci 37(8):1223-1237

Cai X, Zhou Z, Liu K, Du X, Zang H (2019) Water-weakening effects on the mechanical behavior of different rock types: phenomena and mechanisms. Appl Sci 9(20):4450

Carman P (1997) Fluid flow through granular beds. Chem Eng Res Des 75(1 SUPPL.):S32-S46 
Castellanza R, Nova R (2004) Oedometric tests on artificially weathered carbonatic soft rocks. J Geotech Geoenviron Eng 130(7):728-739

Cilona A, Baud P, Tondi E, Agosta F, Vinciguerra S, Rustichelli A, Spiers CJ (2012) Deformation bands in porous carbonate grainstones: field and laboratory observations. J Struct Geol 45:137-157

Forest S, Blazy J-S, Chastel Y, Moussy F (2005) Continuum modeling of strain localization phenomena in metallic foams. J Mater Sci 40(22):5903-5910

Holcomb DJ, Olsson WA (2003) Compaction localization and fluid flow. J Geophys Res Solid Earth 108(B6)

Klein E, Baud P, Reuschlé T, Tf Wong (2001) Mechanical behaviour and failure mode of bentheim sandstone under triaxial compression. Phys Chem Earth Part A Solid Earth Geodesy 26(1):21-25

Kozeny J (1927) Über kapillare leitung des wassers im boden. Sitzungsberichte Wiener Akademie 126:271-306

Lepique M (2008) Empfehlung nr. 10 des arbeitskreises 33 "versuchstechnik fels" der deutschen gesellschaft fur geotechnik e. v.: Indirekter zugversuch an gesteinsproben-spaltzugversuch. Bautechnik 85(9):623-627

Menéndez B, Zhu W, Wong T-F (1996) Micromechanics of brittle faulting and cataclastic flow in berea sandstone. J Struct Geol 18(1):1-16

Oka F, Kimoto S, Higo Y, Ohta H, Sanagawa T, Kodaka T (2011) An elasto-viscoplastic model for diatomaceous mudstone and numerical simulation of compaction bands. Int J Numer Anal Methods Geomech 2008:244-263

Olsson WA, Holcomb DJ (2000) Compaction localization in porous rock. Geophys Res Lett 27(21):3537-3540
Papazoglou A (2018) An experimental study of localized compaction in high porosity rocks : the example of Tuffeau de Maastricht. $\mathrm{PhD}$ thesis, Université Grenoble Alpes

Papazoglou A, Shahin G, Marinelli F, Dano C, Buscarnera G, Viggiani G (2017) Localized compaction in tuffeau de maastricht: Experiments and modeling. In: Papamichos E, Papanastasiou P, Pasternak E, Dyskin A (eds) Bifurcation and degradation of geomaterials with engineering applications. Springer, New York, pp 481-488

Papka S, Kyriakides S (1999) Biaxial crushing of honeycombs-part 1: experiments. Int J Solids Struct 36(29):4367-4396

Sternlof K (2006) Structural geology, propagation mechanics and hydraulic effects of compaction bands in sandstone. $\mathrm{PhD}$ thesis, Stanford University

Vajdova V, Baud P, Wu L, Wong T-F (2012) Micromechanics of inelastic compaction in two allochemical limestones. J Struct Geol 43:100-117

Vergara MR, Balthasar K, Triantafyllidis T (2014) Comparison of experimental results in a testing device for swelling rocks. Int $\mathbf{J}$ Rock Mech Min Sci 66:177-180

Publisher's Note Springer Nature remains neutral with regard to jurisdictional claims in published maps and institutional affiliations. 